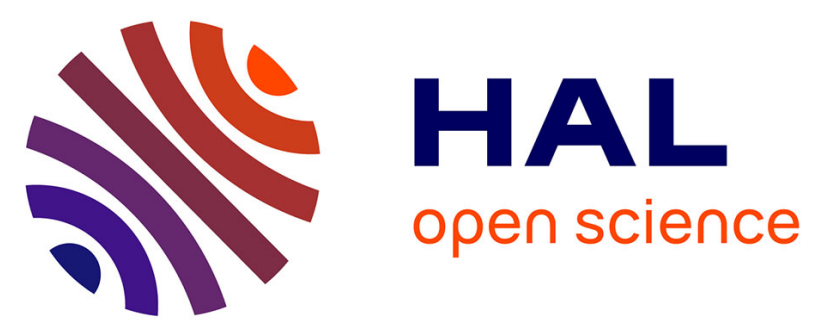

\title{
Modeling of DC-biased hysteresis loops with the GRUCAD description
}

R Jastrzębski, A Jakubas, K. Chwastek

\section{To cite this version:}

R Jastrzębski, A Jakubas, K. Chwastek. Modeling of DC-biased hysteresis loops with the GRUCAD description. 15th International Workshop on 1\&2-Dimensional Magnetic Measurement and Testing2DM Conference, Sep 2018, Grenoble, France. hal-01885843

\section{HAL Id: hal-01885843 https://hal.science/hal-01885843}

Submitted on 2 Oct 2018

HAL is a multi-disciplinary open access archive for the deposit and dissemination of scientific research documents, whether they are published or not. The documents may come from teaching and research institutions in France or abroad, or from public or private research centers.
L'archive ouverte pluridisciplinaire HAL, est destinée au dépôt et à la diffusion de documents scientifiques de niveau recherche, publiés ou non, émanant des établissements d'enseignement et de recherche français ou étrangers, des laboratoires publics ou privés. 


\title{
Modeling of DC-biased hysteresis loops with the GRUCAD description
}

\author{
R. Jastrzębski, A. Jakubas, K. Chwastek \\ Faculty of Electrical Engineering, Częstochowa University of Technology \\ Faculty of Electrical Engineering, Częstochowa University of Technology, Al. Armii Krajowej 17, \\ 42-201 Częstochowa, Poland, e-mail: krzysztof.chwastek@gmail.com
}

\begin{abstract}
The paper considers the description of DC-biased minor loops with the GRUCAD model. The model is given in the form of a combination of nonlinear and ordinary differential equations, what bears resemblance to the well-known Jiles-Atherton formalism. However the model behaves in a qualitatively different way than the original Jiles' proposal. The paper points out the differences between both approaches and presents the results of modeling for biased hysteresis loops of a Soft Magnetic Composite core.
\end{abstract}

\section{Introduction}

Excitation signals for magnetic circuits in real-life conditions may differ significantly from those prescribed in appropriate standards e.g. IEC-60404. One of the most common situations is the presence of DC offset signal, which in extreme cases may cause malfunction of power engineering transformers due to geo-magnetically induced currents [1,2]. Biased magnetization patterns are also an important tool for material characterization for scientists with different background and engineers working on practical use of magnetic circuits in electrical and electronic devices [3-6]. Thus it can be stated that prediction of power losses and shapes of hysteresis curves under distorted induction waveforms is an important subject of study even nowadays.

The similarity of magnetization curves has been noticed and described for the first time by E. Madelung [7]. His concepts have been transformed into a number of useful engineering approaches to model first and higher order reversal curves [8-15]. It should be remarked that some of the aforementioned methods rely extensively on the hysteresis model used in the analysis.

Among different hysteresis models the Preisach-Mayergoyz description [3] and the formalism advanced by Jiles and Atherton [16] have attracted a lot of attention. Despite some attractive features of the latter model (low dimensionality, ease of numerical implementation), the scientific community has become soon aware that it required a number of refinements and updates of the values of model parameters in order to model DC-biased minor loops accurately [17,18].Another puzzling model behavior has been noticed for sudden field reversals, namely the presence of loop fragments with negative susceptibility. This particular feature might be an obstacle for implementing this description in Finite Element Method (FEM) codes [19-21]. The problems with the original Jiles-Atherton (JA) description may be overcome by replacing it with an alternative formulation, namely the GRUCAD description.

The GRUCAD model has been called by its developers, the Brazilian research group ,,a modified Jiles method" [22]. We believe the introduced modifications are so significant that this description deserves its own name. The GRUCAD model indeed resembles to some extent the original JA 
approach in the sense that it is formulates in the form of ordinary differential equations and additional nonlinear relationships and it has just five parameters. Physical interpretation may be assigned to most of its parameters. An important qualitative feature of the description is that the irreversible and reversible magnetization effects are decoupled. In the original JA model some problems related to the $c$ parameter responsible for the reversible behavior have been noticed [23]. Even when the relationship for total susceptibility was replaced from a simple sum of irreversible and reversible magnetization contributions to the form resembling the product Preisach model and representation of minor loops was significantly improved [18], there existed an implicit coupling in the modified JA model through the so-called effective field. This resulted in the necessity to retain the pseudo-parameter $\delta_{M}$ inherited from the original model, whose role was to cut off the irreversible magnetization term in certain fragments of the $M-H$ plane.

The set of considered equations for the GRUCAD model is as follows:

$$
\begin{gathered}
H_{\mathrm{an}}=B / \mu_{0}-M_{\mathrm{s}}(\operatorname{coth} \lambda-1 / \lambda) \\
\lambda=\frac{1}{a}\left[(1-\alpha) H_{\mathrm{an}}+\alpha \frac{B}{\mu_{0}}\right] \\
\frac{\mathrm{d} H_{\mathrm{h}}}{\mathrm{d} B}=\frac{H_{\mathrm{HS}}\left(\operatorname{coth} \lambda_{\mathrm{H}}-1 / \lambda_{\mathrm{H}}\right)+H_{h}}{\gamma \delta} \\
\lambda_{\mathrm{H}}=\frac{H_{\mathrm{h}}+\delta H_{\mathrm{HS}}}{a} \\
H=H_{\mathrm{an}}+H_{\mathrm{h}}
\end{gathered}
$$

Herein $\delta=\operatorname{sign}(\mathrm{d} B / \mathrm{d} t)= \pm 1$, whereas $\alpha, a, \gamma, H_{\mathrm{HS}}$ and $M_{\mathrm{s}}$ are model parameters.

The parameter $\alpha$ should not be confused with the mean field parameter in the Jiles theory. Here it plays the role of a weighting parameter between the model input (magnetic induction B expressed in the units of field strength) and the anhysteretic field strength, cf. Eq. 2. Since there is no coupling between equations describing the reversible (Eqs. (1) and (2)) and irreversible phenomena (Eqs. (3) and (4)), the slope of any magnetization curve after a reversal is equal to the slope of the virgin curve (which should be a positive value, as it follows from Rayleigh relationships).

As pointed out earlier, the model input variable is magnetic induction $B$. The model output is total field strength $H$. It means this description may be easily incorporated in two dimensional FEM codes based on magnetic vector potential $\stackrel{\mu}{A}(\overleftrightarrow{B}=\operatorname{rot} \vec{A})$, where magnetic induction is known ahead of field strength. It is also straightforward to include the model in loss computations based e.g. on Bertotti's theory $[6,24]$. It should be recalled that in magnetic measurements carried out in accordance with the international standards like IEC 60404, the shape waveform of magnetic induction is controlled [25]. It means that measurement data may be used as a direct input for the GRUCAD model.

In a previous publication [26] yet another important advantage of the GRUCAD description has been noticed: there was no need to update the values of model parameters for symmetrical minor loops. On the contrary, the values of JA model parameters have to be modified for minor loops and higher order reversal curves [13, 17, 18].

The aim of the present paper is to elucidate the possibilities of the GRUCAD approach to describe asymmetric (DC-biased) minor loops in self-developed soft magnetic composite cores.

\section{Material and measurements}

The cores made of self-developed soft magnetic composites were used for tests. In order to make up the cores iron powder (99.5\% wt.) and vinyl polychloride powder $(0.5 \% \mathrm{wt}$.) were mixed and hot pressed. The preliminary tests revealed that the magnetic properties did not differ much for excitation 
frequencies up to $50 \mathrm{~Hz}$. Thus in subsequent tests the magnetization curves obtained at mains frequency $(50 \mathrm{~Hz})$ were treated as quasi-static ones. For measurements a fully automated Remacomp C-200 setup was used. The setup makes it possible to measure magnetization curves that include a biased DC $H$-signal. At first the core was magnetized up to technical saturation, which for the examined sample was obtained at approximately $B_{\max }=1 \mathrm{~T}$. The major loop was recorded. The model parameters were estimated using the Particle Swarm Optimization method. In previous work it has been shown that this optimization method is simple to use and yields acceptable results in a short time [27]. The obtained values of model parameters are reported in Table 1. The measured and modeled major loops are presented in Figure 1.

Table 1. Estimated model parameters

\begin{tabular}{ccccc}
\hline$\alpha(-)$ & $a(\mathrm{~A} / \mathrm{m})$ & $M_{\mathrm{s}}(\mathrm{A} / \mathrm{m})$ & $\gamma(\mathrm{T})$ & $H_{\mathrm{Hs}}(\mathrm{A} / \mathrm{m})$ \\
\hline 0.0132 & 6600 & $1.4 * 106$ & 0.08 & 337 \\
\hline
\end{tabular}

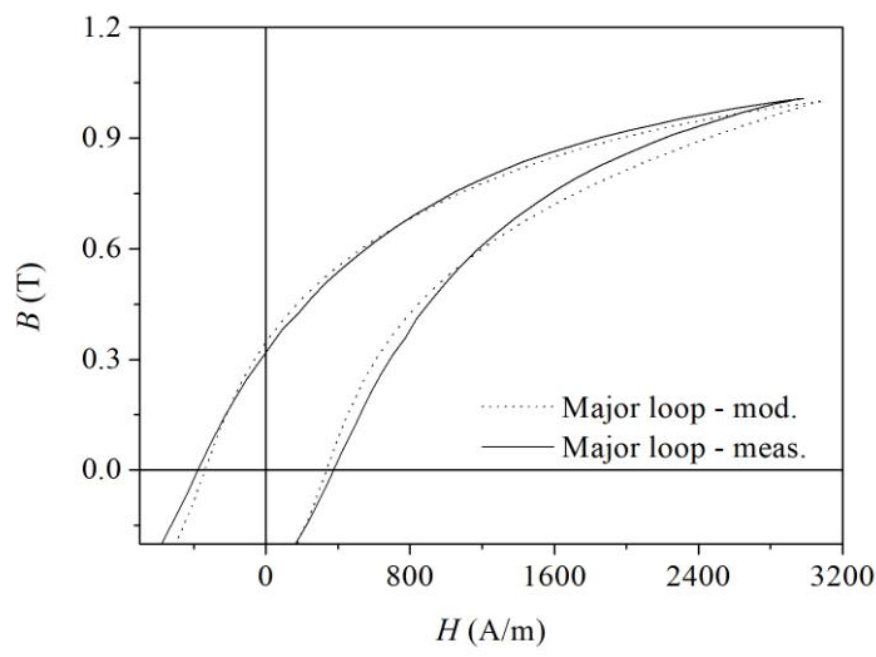

Fig. 1. Measured and modeled major loop

Table 2. Errors for modeled major loop

\begin{tabular}{ccc}
\hline$B_{\max }$ & $H_{\max }$ & $\Delta \mathrm{P}$ \\
\hline $1 \%$ & $2.9 \%$ & $3.1 \%$
\end{tabular}

Next a minor loop with amplitude $B_{\max }=0.5 \mathrm{~T}$ was measured. In the subsequent tests the core was subject to external field excitation that included additional bias signals with effective amplitudes $B_{\max }=0.72 \mathrm{~T}$ and $B_{\max }=0.86 \mathrm{~T}$ were recorded. Modeling of minor DC-biased loops was carried out using the set of model equations (1)-(5), values of model parameters from Table 1 and Matlab event location feature present in Ordinary Differential Equation toolbox in order to match the amplitudes of modeled loops to the measured ones. The modeling results are presented in Figures 2 and 3. It can be stated that the modeled magnetization curves resemble to much extent the measured ones. 
Table 3. Errors for $U_{\text {bias }}=50 \mathrm{mV}$

\begin{tabular}{ccccc}
\hline$B_{\max }$ & $B_{\min }$ & $H_{\max }$ & $H_{\min }$ & $\Delta \mathrm{P}$ \\
\hline $0.83 \%$ & $0.4 \%$ & $13.8 \%$ & $2.44 \%$ & $41 \%$ \\
\hline
\end{tabular}

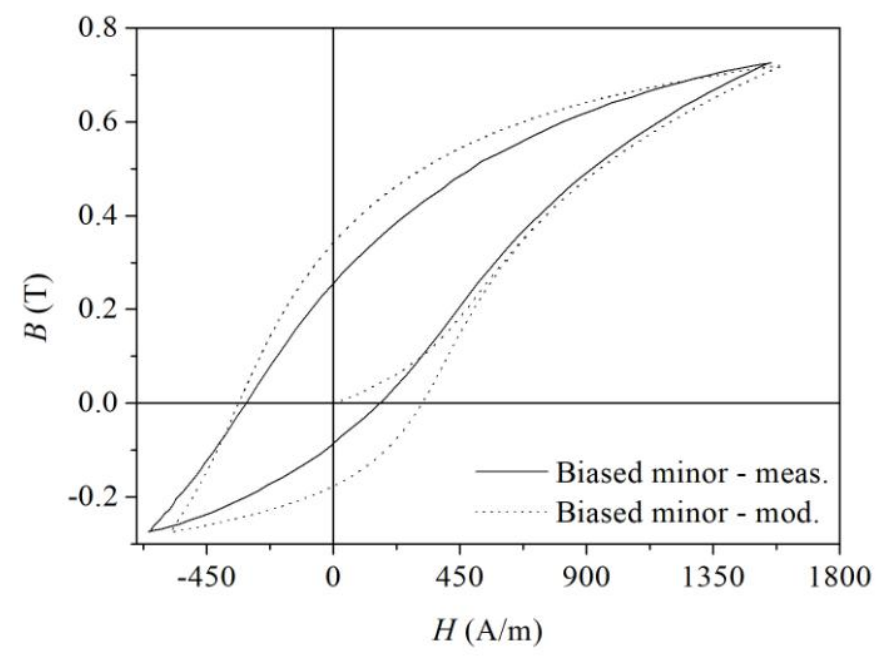

Fig. 2. Measured and modeled DC-biased minor loops for $B_{\max }=0.72 \mathrm{~T}$.

Table 4. Errors for $U_{\text {bias }}=100 \mathrm{mV}$

\begin{tabular}{ccccc}
\hline$B_{\max }$ & $B_{\min }$ & $H_{\max }$ & $H_{\min }$ & $\Delta \mathrm{P}$ \\
\hline $1.15 \%$ & $0.73 \%$ & $6.9 \%$ & $4.12 \%$ & $39 \%$
\end{tabular}

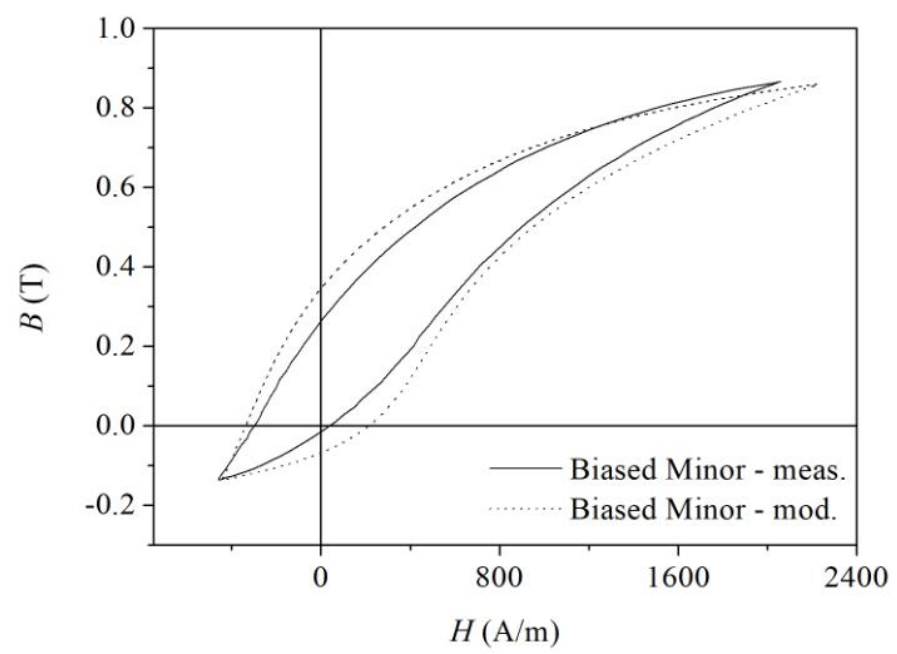

Fig. 3. Measured and modeled DC-biased minor loops for $B_{\max }=0.86 \mathrm{~T}$. 


\section{Discussion}

From Madelung rules it follows that fragments of branches of DC-biased minor loops should coincide or at least tend asymptotically to those for the major loop. This qualitative behavior is illustrated in Figure 4, where both curves modeled with the GRUCAD approach are presented. The values of model parameters are kept intact for the DC-biased loops.

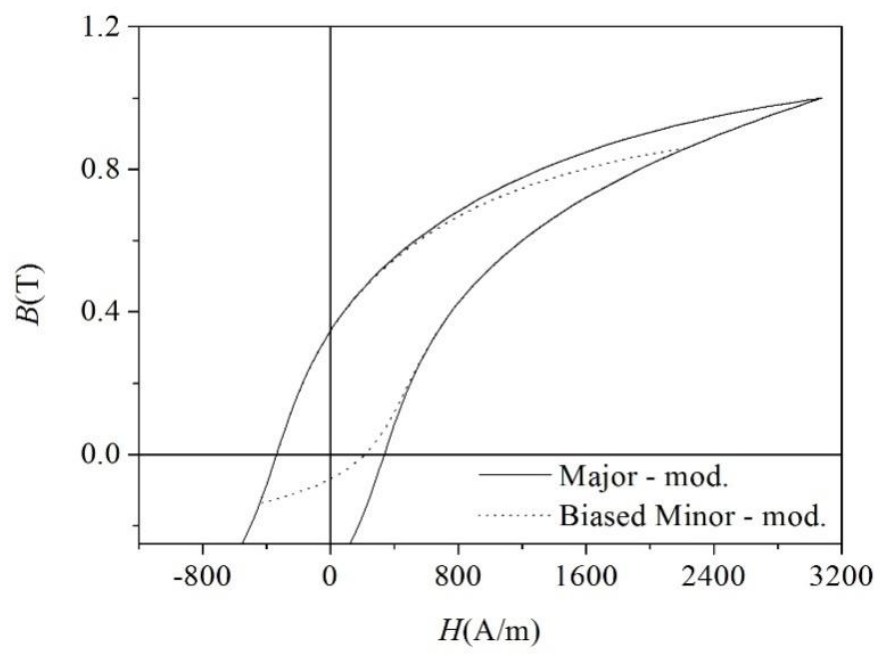

Fig. 4.Modeled major and DC-biased minor loop.

It can be seen from Figure 5 that the ascending branch of the minor loop is equivalent to the ascending branch of major loop with an appropriate offset. It is possible to obtain fragments of any minor loop (either with DC bias or without it) using appropriately offset (,transplanted" [10]) fragments of the major loop. It is desirable that the parameter sets for the major and the minor loops should remain constant.

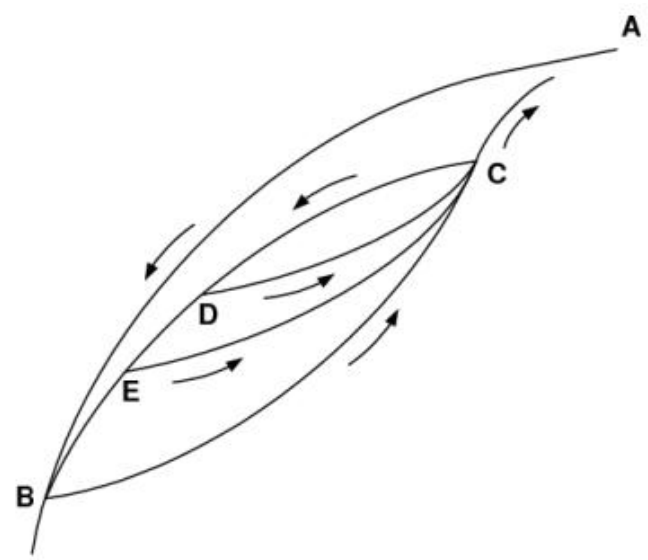

Fig. 5. Behavior of minor loops, reversal point and Madelung rules.

The accuracy of modeled minor loops depends significantly on the quality of major loop representation and the estimated values of parameters. The same parameter set is used to describe all magnetization curves, either symmetrical or biased ones. This is an important advantage of the GRUCAD description in comparison to the Jiles-Atherton model.

Attention should be paid to the fact that despite a very good fitting of the major loop was obtained (3\% relative error for power loss density), the fitting of DC-based minor loops does not look as good as the one for the major loop. The possible reasons for the fact are the measurement errors and 
inaccuracies in determination of the major loop parameters. The shapes of the minor loops are reproduced quite well qualitatively, but there are significant discrepancies in the areas of measured and modeled DC-biased loops.

\section{Conclusions}

In the paper the possibilities to describe minor loops, including those containing DC-bias signal, with the GRUCAD model were considered. It was shown that the values of model parameters for biased hysteresis curves are kept the same as for the major loop. The measured and modeled DCbiased hysteresis curves are in a qualitative agreement. The discrepancies between the modeled and measured minor loops with DC-bias depends on the accuracy of determined major loop parameter and on the amplitude of the minor loop.

\section{References}

[1] P. Price, Geomagnetically induced current effects on transformers, IEEE Trans. Power Deliv. 17 (4) 1002-1008, 2002

[2] S. A. Moussavi, Electromagnetic modelling of power transformers with DC magnetization, Thesis, Royal Institute of Technology (KTH), Stockholm, Sweden 2012

[3] I. D. Mayergoyz, Mathematical models of hysteresis, Springer 1991

[4] Y. Cao, K.Xu, W. Jiang, T. Droubay, P. Ramuhalli, D. Edwards, B. R. Johnson, J. McCloy, Hysteresis in single and polycrystalline iron thin films: major and minor loops, first order reversal curves, and Preisach modeling, J. Magn. Magn. Mater. 395 (2015) 361-375

[5]X. Zhao, A. P. Roberts, D. Heslop, G. A. Paterson, Y. Li, J. Li, Magnetic domain state diagnosis using hysteresis reversal curves, J. Geophys. Res. Solid Earth 122 (2017) 4767-4769

[6] O. de la Barrière, C. Ragusa, C. Appino, F. Fiorillo, Prediction of energy losses in soft magnetic materials under arbitrary induction waveforms and DC bias, IEEE Trans. Ind. Electron. 64 (3) (2017) 2522-2529

[7] E. Madelung, Über Magnetisierung durch schnellverlaufende Ströme und die Wirkungsweise des Rutheford-Marconischen Magnetdetektors, Ann. Phys. 322 (10) (1905) 861-890

[8] S. N. Talukdar, J. R. Bailey, Hysteresis models for system studies, IEEE Trans. Power App. Syst. 95 (4) (1976) 1429-1434

[9] S. R. Naidu, Simulation of the hysteresis phenomenon using Preisach's theory, IEE Proc. A 137 (2) (1990) 73-79

[10] S. E. Zirka, Yu. I. Moroz, Hysteresis modeling based on transplantation, IEEE Trans. Magn. 31 (6) (1995) 3509-3511

[11] J. Takács, Mathematics of hysteretic phenomena, Wiley-VCH, Weinheim 2003.

[12] J. Faiz, S. Saffari, A new technique for modelling hysteresis phenomenon in soft magnetic materials, Electromagnetics 30 (2010) 376 401

[13]K. Chwastek, Higher order reversal curves in some hysteresis models, Arch. Electr. Eng. 61 (4) (2012) 455-470

[14] W. Renhart, O. Biró, Ch. Magele, K. Preis, A. Rabel, Inrush current computations using an optimized analytical hysteresis model, COMPEL 36 (5) (2017) 1568-1576

[15] J. P. A. Bastos, K. Hoffman, J. V. Leite, N. Sadowski, A new and robust hysteresis modeling based on simple equations, IEEE Trans. Magn. 54 (3) (2018) 7300104 (4 pp.)

[16] D. C. Jiles, D. L. Atherton, Theory of ferromagnetic hysteresis, J. Magn. Magn. Mater. 61 (1986) 48-60

[17]A. Benabou, J. V. Leite, S. Clénet, C. Simao, N. Sadowski, Minor loops modelling with a modified Jiles-Atherton model and comparison with the Preisach model, J. Magn. Magn. Mater. 320 (2008) e1034-e1038

[18] K. Chwastek, Modelling offset hysteresis loops with the modified Jiles-Atherton description, J. Phys. D: Appl. Phys. 42 (2009) 165002 (5 pp.)

[19] H. L. Toms, R. G. Colclaser, M. P. Krefta, Two-dimensional finite element magnetic modeling for scalar hysteresis effects, IEEE Trans. Magn. 37 (2) (2001) 982-988

[20] S. E. Zirka, Yu. I. Moroz, R. G. Harrison, K. Chwastek, On physical aspects of the Jiles-Atherton hysteresis models, J. Appl. Phys. 112 (2012) 043916 (7pp.)

[21] R. Jastrzębski, K. Chwastek, A comparison of macroscopic descriptions of magnetization curves, ITM Web of Conferences 15 (2017) 03003, doi:10.1051/itmconf/20171503003

[22] P.I. Koltermann, L.A. Righi, J.P.A. Bastos, R. Carlson, N. Sadowski, N.J. Batistela, A modified Jiles method for hysteresis computation, Physica B 275 (2000) 233-237

[23] A. Benabou, J. V. Leite, S. Clénet, C. Simao, N. Sadowski, Minor loops modelling with a modified Jiles-Atherton model and comparison with the Preisach model, J. Magn. Magn. Mater. 320 (2008) e1034-e1038

[24] G. Bertotti, Hysteresis in magnetism, Academic Press, San Diego 1998

[25] F. Fiorillo, Measurement and characterization of magnetic materials, Elsevier Academic Press, Amsterdam 2004

[26] S. Steentjes, K. Chwastek, M. Petrun, D. Dolinar, K. Hameyer, Sensitivity analysis and modeling of symmetric minor hysteresis loops using the GRUCAD description, IEEE Trans. Magn. 50 (11) (2014), doi: 10.1109/TMAG.2014.2323250

[27] R. Jastrzębski, K. Chwastek, I. Biondić, K. Miličević, A comparison of different estimation methods for hysteresis modelling, Acta Phys. Pol. A 131 (2017) 1228-1231 